\title{
NON-PHARMACOLOGICAL IMMUNOCORRECTION
}

\section{AndreyM. Zemskov ${ }^{1}$, VladimirM. Zemskov*2., VeronikaA. Zemskova ${ }^{1}$., Zoya A. Vorontsova $^{1}{ }^{\text {., YevgeniyV. Dorokhov }}{ }^{1}$ and IgorM.Chernitsyn ${ }^{1}$}

\author{
${ }^{1}$ Voronezh N.N.Burdenko State Medical University, Voronezh, Russia \\ ${ }^{2}$ A.V.Vishnevsky Institute of Surgery, Moscow, Russia
}

DOI: http://dx.doi.org/10.24327/ijrsr.2017.0805.0291

\section{ARTICLE INFO}

\section{Article History:}

Received $18^{\text {th }}$ February, 2017

Received in revised form $10^{\text {th }}$

March, 2017

Accepted $06^{\text {th }}$ April, 2017

Published online $28^{\text {th }}$ May, 2017

Key Words:

Non-pharmacological, Immunocorrection

\begin{tabular}{l} 
ABSTRACT \\
\hline This review article describes various methods of non-pharmacological immunocorrection- \\
membranous, gravitation, sorptive, electrochemical, physiotherapeutical, extracorporal and \\
acupuncture, balneological, speleological, modification and others.
\end{tabular}
acupuncture, balneological, speleological, modification and others.

Copyright (C) AndreyM. Zemskov et al, 2017, this is an open-access article distributed under the terms of the Creative Commons Attribution License, which permits unrestricted use, distribution and reproduction in any medium, provided the original work is properly cited.

\section{INTRODUCTION}

Currently wide use of immunotropic preparation is restrained by their poor choice, deficiency of active preparations, their significant expensiveness in specific cases, side effects, severe course of diseases in many cases, resistance to drug therapy with concomitant drug intolerance. One of the solutions for this challenge is considered to be application of nonpharmacological therapies (Zemskov et al., 2016).

non-pharmacological immunocorrection methods can be classified as membranous (hemoimmunocorrection, hemodialysis, ultra- and hemofiltration, plasmolymphodialysis, cytapheresis); gravitation (plasmapheresis, leukocytopheresis, thrombocytopheresis, erythrocytopheresis, lymphocytopheresis); sorptive (hemo-, immuno-enterosorption, splenoperfusion); physiotherapeutical (magnetic fields, ultrasound irradiation of organs of immunogenesis); photomodification of blood (low level laser therapy, ultraviolet blood irradiation (UBI); electrochemical hemoimmunotherapy (ozonization of solutions, blood, indirect electrochemical oxidation by sodium hypochlorite); extracorporal; acupuncture; sanatorium resort therapy-balneo-, speleotherapy; others (bloodletting, autohemotherapy) (Zemskov et al., 2016; Novikova, Zemskov, 1998).

\section{Sorptive methods}

\section{Hemosorption}

This method is applied to extract toxic substances from blood by activated carbon. It is used for treatment of idiopathic fibrosing alveolitis, Loffler's syndrome, Felty's syndrome, systemic sclerodermia, Wegener's granulomatosis, systemic lupus erythematosis (SLE) etc. Mechanism of hemosorption is based on the alteration of functional status of immunocompetent blood cell receptors, unblockage of bronchial $\beta$-adrenoreceptors to restore sensitivity to sympathomimetic preparations, glucocorticoids (Zemskov et al., 2002b).

\section{Immunosorption}

Development of specific sorbents with high level of affinity to components subjected to be removed from peripheral blood is reported to be one of the ways to further improve hemosorption. Immunosorption based on the interrelations of antigens with antibodies that are fixated on an insoluble carrier, through which solution is perfused, appears to be the most specific.

\section{Enterosorption}

Enterosorption is based on binding and removal of endogenic and exogenic substances, supramolecular structures and cells 
from gastro-intestinal tract. Moreover, a 2-3 day course of enterosorption may be compared with one session of hemosorption on the intensity of detoxification effect. Adsorbents, absorbents, ion-exchange materials and sorbents with catalytic properties include activated carbons, silicagels, zeolites, aluminum hydroxides, aluminum silicates, oxide sorbents, dietary fibres, organomineral and compositional sorbents. They realize selective, monofunctional, selective biand polyfunctional and non-selective sorption. The mechanisms of enterosorption are as follows: elimination of back passage of toxic agents from the intestine into blood; purification of digestive juices with modification of lipid and aminoacid range; removal of toxic substances-indole, skatole, and phenols; decrease of functional load on the liver. It should be noted that enterosorbents do not practically alter the composition of the normal intestinal flora but adsorb toxic products, food-borne allergens, histamine, bacterial antigens, and circulating immune complexes (CIC). This combines with decrease amount of total protein, gamma-globulins, thymol test, concentration of antibodies, bilirubin, ALAT level and ASAT activity in blood; alkaline phosphatase, accumulation of albumin, cortisol. Moreover, food-borne allergens, histamine, bacterial antigens, CIC, decrease of excess level of antibodies, activation of cortisol release etc. are noted to be bound. The prolonged action of enterosorption results in negative balance of vitamins $\mathrm{A}, \mathrm{E}, \mathrm{C}$, protein assimilation and absorption is delayed; nitrogen excretion with faeces is increased.

\section{Splenoperfusion}

Xenospleen is used as a biological immunomodulator. This organ is known to play an essential role in phagocytosis, antigen processing and presentation by macrophages, T- and Bcells immune reactions, anti infectious résistance formation, and removal of immune complexes, formation and activation of T-cytotoxic suppressors. SLE-titres of anti-DNA-antibodies, concentration of C-reactive protein, fibrinogen, ESR, IgG are reported to decrease, the amount of T-lymphocytes and their regulatory subpopulations are reported to increase after 3-4 sessions of blood perfusion of a patient through isolated xenospleen, especially that of a pig. With that a daily prednisolone dosage may be reduced in almost two times.In patients with purulent-septic disorders and rheumatic disease the essential clinico-immuno-corrective effect is obtained in $70-80 \%$ of cases, which is manifested in normalization of the amount and function of CD3, CD71, CD4, CD8, CD16lymphocytes, B-cells, expression of HLA-DR-antigens on the cells, complement, phagocytosis, IL-2.

Physiotherapeutic methods (Goryainov, 1999)

\section{Low level laser therapy}

(LLLT) is widely applied almost in all fields of medicine. The most common laser devices are considered to be a helium-neon laser irradiating red light; a helium-cadmium laser generating blue light; infrared semiconductor lasers. Currently there are following techniques of laser therapy: topically, epidermally on the projection of an abnormal focus or focus through acupoints or Zakharyin-Ged reflexogenic zones; directly on the abnormal focus using endoscopic devices; indirect impact on an abnormal intravascular laser irradiation of blood; direct impact on immunocompetent cells-leuco-lympho-mass irradiation (Zubkova, 1996).
LLLT spectrum of action covers factors of non-specific antiinfectious resistance: lysozyme, the complement system, phagocytosis, and interferon. Certain impact on specific immune reactions and their cells - antibody-forming cells, immunoglobulins, especially $\operatorname{IgG}$ and $\operatorname{IgA}$, T-lymphocytes, their regulatory sub-populations, B-cells etc. - has been proved to exist. Reticulocytosis, granulocytosis, lymphocytosis are observed after total irradiation. It is assumed that increase amount of stab neutrophils is related to leucopoiesis activation, and increase level of T-lymphocytes, basophils, eosinophils results from accelerated release of mature cells from the bone marrow sinuses, spleen, lungs and other white blood cell pools (Alyokhina, 1994).

LLLT is successfully applied to correct immune disorders and achieve a positive clinical outcome in patients with osteomyelitis, cancer, vasomotor rhinitis, neurodermatitis, cutaneous vasculitis, alopecia, rheumatic arthritis, ischemic heart disease, chronic non-specific lung disease, ulcer disease, obstructive jaundice, lactational mastitis, epididymo-orchitis, to prevent complications after Cesarean section and other pathological processes (Konchugova et al., 1977).

\section{Ultrasonic irradiation of spleen and thymusin children}

During 3-5 minutes a day for 10 days, results in migration and function stimulation of peripheral blood T-lymphocytes.

\section{High-frequency therapy and microwave therapy}

This method is subjected to pharyngeal lymphoid ring with palatal tonsils, thyroid and parathyroid glands, carotid sinus, cervical autonomic ganglia and thymus stimulate immune reactivity in patients, decrease risk of post-operative suppurative complications development. These techniques are reported to be the only methods of eliminating immune disorders in case of drug intolerance induction (Greenzaid et al., 1994; Dolgareva, 1998).

\section{Hydro-acupuncture and laser-puncture}

According to Chinese charts (The Chart of national standard of locations of the channel acupoints-GB 12346-90, 1991) this method provide the increase of initially decreased level of lymphocytes, T-cells, T-helper cells (CD4), CD8, Blymphocytes and decrease the excessive amount of leucocytes, IgA, IgG, circulating immune complexes (Chzhu Bin, 1997) when injecting $0.3-0.5 \mathrm{ml}$ of $5 \%$ ascorbic acid solution into selected acupoints on the background of irradiation by a helium-neon optical quantum generator, type ALOU-2 (Russian abbreviation for a cross-functional apparatus for laser irradiation).

\section{Extracorporal immune therapy}

Represents in vitro activation of immunocompetent cellsregulators by any stimulator in patients having pathological processes. This technique is applied when a patient reveals drug intolerance to immunotropic medications, but, at the same time, their administration is life-saving, e.g., in case of Lyell's syndrome. The essence of the technique is as follows: $1-5 \mathrm{bln}$ of peripheral leucocytes are taken from a patient using a fractionator. Next white blood cells are incubated with a modulator, e.g., diuciphonum, in concentration $50 \mu \mathrm{g} / \mathrm{ml}$ at $37^{\circ} \mathrm{C}$ for 3 hours. After that, leucocytes are washed free from a modulator and re-infused into a patient. The course of such a 
treatment usually consists of 1-3 procedures performed in 2-3 days. Positive clinical outcome is achieved in $89 \%$ of cases. Simultaneously the correction of immune disorders, mainly on T-cell and phagocytic components, are carried out. Fundamentally, other immunomodulators also demonstrate similar activity (Zemskov et al., 2016; Fedenko, 1987).

\section{Autotherapy with focus-infiltrating leucocytes}

Appears to be a variant of extracorporal immunotherapy. Research studies performed by K. Zhestkov (1999, 1998a, 1998b) allowed to specify localization of the most preserving immunocompetent cells functioning as effectors of antituberculous immunity in the lungs. Isolation and deposition of these cells and their succeeding introduction to patients result in the expressed correction of immune disorders and achievement of remission.

Schematically developed by the author the technique of isolation of focus-infiltrating leucocytes is considered to be as follows: during the operation in sterile conditions they isolate tissue from a tuberculoma capsule or a tuberculous cavern wall, which is then subjected to "mild" mechanical homogenization. Cellular suspension is divided by centrifugation in a specially chosen velocity sedimentation gradient of ficoll-verografin. After that suspension is repeatedly washed free by sedimentation-resuspending in the nutritional medium with rifampicin, which little affects leucocytes viability in vitro being taken in bactericidal concentration. The obtained lymphocyte suspension is incubated, and morphology and viability of cells are investigated. A part of fraction is studied microbiologically to detect Mycobacterium tuberculosis and non-specific flora; one more part is investigated using an immunofluorescent technique to specify a population structure of the obtained fraction. The residual, major part of the isolated lymphocytes is put into the nutritional medium and stored until results of the bacteriologic examination are obtained. After the sterility of the cell culture is confirmed, cells are divided by a plate method. Antibodies immobilized on the grid bind Thelpers sedimentating on the bottom; non-bound cells are placed into the buffer physiological saline and re-infused to a patient. Attached cells are removed from plastic to be further incubated with auto blood cells. In the post-operative period they take $20-40 \mathrm{~cm}^{3}$ of venous blood from a patient and isolate lymphocytes out of this blood. These lymphocytes are then incubated with CD4+ lymphocytes from the focus of tuberculous inflammation removed from plastic in sterile conditions.

Thus, 4.8-6.6 $\mathrm{mln} / \mathrm{cm}^{3}$ of lymphocytes may be obtained in average from the lung resectate; their viability constitutes 88 $94 \%$. In addition, invert correlation of the isolated cell amount and their viability with duration of tuberculous process in the lung was revealed: the less was the duration of tuberculous process, the larger amount of viable cells might be obtained. The bacteriological examination has proved that culture of focus-infiltrating leucocytes contained neither Mycobacterium tuberculosis detected by a fluorescent technique nor nonspecific flora detected by a bacteriologic culture technique in any of 75 cases. Gravitational sterilization occurs during the process of isolation in the velocity sedimentation gradient and in succeeding repeated centrifugations; because of the different sedimentation constant, lymphocytes appear in the sediment and bacteria remain in a supernatant. This fact is proved by the bacteriological examination of supernatant fluid.

\section{Transplantation of autoleucosuspension}

Essential local dysimmunity, reduced activity of alveolar macrophages, neutrophils and other cells are common in chronic inflammatory lung diseases. Against this background, introduction of autoleucosuspension of peripheral leucocytes, whose function is not damaged by inhibiting factors of lung origin, into the lungs of a patient appears to be a promising approach (Zemskov et al., 2002a).

The following criteria were considered to be indications for treatment of patients with bronchitis:

1. Stable bronchial obstruction in spite of the performed pharmacological therapy (for 5-7 days).

2. Breathlessness, non-productive intensive cough combined with dry rales in the lungs in auscultation.

3. Purulent sputum in patients with local moist and dry rales in absence of infiltrative changes on the roentgenogram.

4. Prolonged subfebrility combined with decreased vesicular breath sounds in auscultation in patients with bronchial syndrome.

Endobronchial sanation with autological leucocytic suspension prepared extempore was performed by the introduction of $4 \mathrm{ml}$ leucocytic suspension in plasma after spontaneous erythrocyte sedimentation $(1 \mathrm{~g})$ as a result of 2-hour incubation of patient's venous blood in the tube bended under $45^{\circ}$ in a thermostat at the temperature $37^{\circ} \mathrm{C}$. Leucosuspension was irradiated by a low-energy laser "TPLA-1" (Russian abbreviation) with the wave length equal $632.8 \mathrm{~nm}$ and $1.5 \mathrm{mWat}$ power at the discharge end of the flexible quartz-polymer light guide for 7 minutes. $1 \mathrm{ml}$ of prednisolone was added to leucosuspension; it was introduced into a patient during a therapeutic bronchoscopy. The course of treatment included 2-4 sanations performed in 1-3 days.

\section{Therapeutic plasmapheresis}

Is known to be fractional blood exfusion, separation of blood cells from plasma with the subsequent re-infusion of formed elements to patients with disorders resulting in formation of an autoimmune component or other disorders like autoimmune hemolytic anemia, idiopathic thrombocytopenic purpura, various types of nephritis, SLE etc. Plasma is removed and replaced with donor plasma or plasma-replacing solutions: lowmolecular dextrins, polyvinyl pyrrolidone, $5 \%$ albumin solution and others. Immunocorrecting effect of therapeutic plasmapheresis is realized through the following mechanisms:

1. elimination of the excessive amount of circulating immune complexes, which also includes deblocking natural ways of excretion of antibodies, antigens, average weight molecules, cellular and tissue debris;

2. restoration of T-lymphocytes activity as a result of possible receptor deblocking and the removal of $\mathrm{T}$ suppressor activity;

3. strengthening of phagocytic capacity of neutrophils and alveolar macrophages;

4. normalization of energetic enzyme systems of lymphocytes; 
5. increase of reduced amount of T-lymphocytes, Tcytotoxic suppressors, T-helpers, T-killers, B-cells, immune globulins of basic classes and others (Kuno, 1994).

Therapeutic plasmapheresis is performed continuously using a special device PF-05 (Russian abbreviation), a blood fractionator DIDECO-BT 798-DE or discretely using PS-6 and TSPRP-5-01 centrifuges (Russian abbreviation) according to established procedures. 1-1.5 volumes of circulating plasma are eliminated during the course of treatment consisting of 3-5 procedures. Plasma correction is performed with physiological salt solution. It should be noted that $1.4 \%$ of procedures was accompanied by transfusion reactions manifested as chills and moderate hypotonia, which were easily neutralized by warming of a patient and introduction of antihistaminic agents.

\section{Ultraviolet blood irradiation (UBI)}

Is used to increase positive effect of therapeutic plasmapheresis. The following mechanisms are known to be of great importance among the great variety of mechanisms of this non-therapeutic method: anti-inflammatory, desensitizing, immune-stimulating, general strengthening; activation of cellular and humoral components of the immune system, factors of non-specific antiinfectious resistance, increase of Tand B-cells amount, increase of their activity, especially those of T-component; potentiation of IgM synthesis; stimulation of the complement system; disintoxication effect and others.

UBI is carried out by the flow-through method in the contour with magnetic treatment of blood (sequentially). Whole blood in the amount of $1.5-2 \mathrm{ml}$ per $1 \mathrm{~kg}$ of a patient's body weight is exposed to UV-rays (wavelength is $256 \mathrm{~nm}$, the source of irradiation is 0 lamp DRB-8 (Russian abbreviation)) with barbotage the ozone and oxygen mixture. Magnetic treatment is sometimes performed by the "PEMP" device (Russian abbreviation), which results in $50 \mathrm{~Hz}$ alternative magnetic field. All the above mentioned extracorporal interventions are performed in the operating room.

\section{Other methods of non-pharmacological immunocorrection}

\section{Hyperbaric oxygenation}

Oxygen capacity to actively influence the diverse compartments of human body activity has been stated recently. There have been specified certain immunocorrecting and other effects: for example, introduction of chemotherapeutic preparations simultaneously with hyperbaric oxygenation therapy (HOT) is widely used in children with blood diseases. Cytostatic side effects are not fully manifested in these conditions; their efficiency is increased that helps reduce doses and duration treatment course of these preparations. It should be highlighted that positive effect of HOT to a great extent depends on pressure conditions, duration of action, an immunogenesis stage and other causes. Depending on this, either stimulation or suppression of immune reactions may occur. Currently this problem, certainly in terms of the immune reactivity, is only outlined, and no adequate detailed research studies are performed (Zemskov et al., 2002b).

Fundamentally different effect of HOT is determined in conditions of thymic-dependent and thymic-independent antigens immunization. Thus, suppression of antibodies formation was registered in case of thymic-dependent antigen immunization when using hyperoxia in the inductive period of antibody-genesis and stimulation on the peak and in later terms of antibodies formation. In case of thymic-independent antigen immunization activation of antibodies formation was performed under HOT impact into inductive and productive phases of antibodies synthesis. However, later oxygen effect under elevated pressure was minimal. It appears that currently we can discuss "hyperbaric" oxygen capacity to modulate the expressiveness of immune reactions depending on certain reasons and conditions, but there is so far lack of concrete findings on correction (elimination) of immune disorders due to this effect in cases of pathological processes. Indeed, inhibition of immune globulin synthesis may be helpful and stimulation may be harmful when developing allergies of I-II-III-IV types in patients. In patients with the deficiency of a humoral component of the immune system the situation is inversed. It is not argued when a patient has toxicosis since activation of nonspecific and specific resistance of hyperbaric oxygenation has been definitely proved. Apparently, the same should be said about HOT use in case of burns and other emergencies. As for other nosologies, a lot should be done to introduce hyperbaric oxygenation into a category of non-pharmacological correctors of immune disorders.

\section{Application of ozonized solution of sodium chloride}

Perfusion of ozonized solution of sodium chloride to patients with inflammatory disorders of the urogenital system causes elimination of the immunosuppressive action of an operational trauma, corrects disorders of the major components of the immune system-cellular, humoral, phagocytic; stimulates nonspecific antiinfectious resistance, decreases inflammation signs, realizes bacteriostatic and bactericidal effect, improves patients' clinical state.

Schematically the technique of parenteral introduction of ozonized solutions is as follows: normal saline is chosen as an ozone carrier; ozone concentration in the solution does not exceed $1000 \mu \mathrm{g} / 1$, a total single dose is $250-500 \mu \mathrm{g}$. Ozonized solution is prepared directly prior to infusion. Ozone is received with an ozonation plant by passing medically pure oxygen through an ionized camera of an ozonator; it is then processed by $400.0 \mathrm{ml}$ of normal saline solution using barbotage technique (active mixing). Ozone concentration in the solution is controlled by the iodometry technique. Ozonized solution should be used during the first 30 minutes after preparation (Kuzmenko, 1997).

\section{Thermotherapy for treatment of children with chronic pneumonia}

Mechanism of the sauna therapeutic action consists of intensive thermal strain on the human body with subsequent contrast cooling by water procedures. Increase of human body temperature is known to be one of the early immune reactions. The experiment demonstrates the decrease of vital activity of pathogenic microorganisms resulted from hyperemia in infected animals. Elevation of the body temperature in mammals is accompanied by activation of phagocytosis, production of antibodies, mobilization of leucocytes, increased interferon and steroid hormones formation. Combination of intensive thermal effect with contrast water procedures (shower, swimming pool) has stimulating and training effect on 
the state of thermoreception and vegetative adaptation. The above mentioned mechanism of action favourably influences major hygienic mechanisms of a pathological process in patients with prolonged and chronic forms of non-specific inflammatory bronchopulmonary diseases and in people predisposed to these conditions.

When a person is in a warm climatic chamber of a sauna, thermal strain primarily results from the impact of the inhaled hot air on his bronchopulmonary system. The surface of this system contacting with the ambient air is known to exceed the skin surface in 40 times. In addition, air exchange activated by the warmth impact constantly persists in the airways, whereas air convection over the skin surface is slightly expressed. Due to this local hyperthermia with activation of thermoregulating mechanisms is developed in the respiratory system. Local hyperthermia eliminates bronchospasm, has bronchodilative effect and improves the respiratory act dynamics as a result of the increased plasticity of thoracic tissues, especially those of the osteo-ligamental apparatus. Thermal therapy includes 8-9 procedures at the temperature $28-30^{\circ} \mathrm{C}$ in children older than 10-15 years. After hygienic shower and subsequent wiping with a dry towel a patient is placed into a sauna for 5-8 minutes twice with a 5-minute interval. After sauna a patient has contrast baths in a swimming pool. Saunatherapy results in a significant increase of T-cells, T-activated leucocytes, Thelpers amount.

\section{Balneotherapy (Klimov, 1993)}

\section{Sulfide balneotherapy}

This method in patients with atopic dermatitis and true eczema results in normalized amount of leucocytes, lymphocytes, Tcells, B-lymphocytes, T-cytotoxic suppressors, and a blasttransformation reaction to phytohemagglutinin (PHA) and IgE; it inhibits lympholeucocytolysis reactions to milk, egg, hake, anti-streptolysin $\mathrm{O}$ and anti-strepto-hyaluronidase allergens.

\section{Radon balneotherapy}

This method in abovementioned patients results in normalized level of T- and B-cells, T-helpers, T-suppressors, E-rosetteforming neutrophils, immune globulins of the major classes, lysozyme.

\section{Autohemotherapy}

Provides an anti-inflammatory, detoxication, general strengthening, immunocorrective effect in a wide range of disorders including purulent infections of soft tissues, deep pyoderma, inflammatory gynecological processes, disorders of the urogenital systems and others.

There have been developed the following schemes of auto blood introduction: $100-300 \mathrm{ml}$ of venous blood is taken from operated patients the next day after the operative intervention; the blood is placed in hermetic plastic bags with a standard additive. Contra-indications for exfusion are considered to be the reduced level of hemoglobin less than $100 \mathrm{GM} / \mathrm{DL}$, the reduced amount of erythrocytes less than $8.0 \cdot 10^{12} / \mathrm{l}$, blood pressure finding less than $100 \mathrm{ml} / \mathrm{Hg}$, the age of a patient more than 75 years. Patients are introduced auto blood reinfusion intravenously in 48-72 hours. There has been registered a positive impact of the procedures on cellular and phagocytic components of the immune system.
The second variant of autohemotherapy suggests taking venous blood in patients and its following daily intramuscular injections on the scheme: $2.0 \rightarrow 4.0 \rightarrow 6.0 \rightarrow 8.0 \rightarrow 10.0 \rightarrow$ $10.0 \rightarrow 8.0 \rightarrow 6.0 \rightarrow 4.0 \rightarrow 2.0 \mathrm{ml}$. Such an affect corrects violation of haemogram, results in normalized amount of Blymphocytes, circulating immune complexes, absorbing and metabolic phagocytic activity.

\section{Bloodletting}

Bloodletting is known to be the most ancient of all therapeutic and preventive measures respected and rejected in various periods of the development of human society; for a long time it did not have proper theoretical and experimental background. Professor M.V.Zemskov and Doctor of Medical Sciences N.V.Zhuravlyova to certain extent specified the mechanisms of bloodletting effects on experimental models (Zemskov, Zhuravlyova, 1977). The above mentioned effect results in stimulation of the humoral component of the immune system and potential response to vaccines when performing 2-3 blood samplings constituting $0.5 \%$ of the total circulating blood volume. However, performance of 4-5 effusions leads to accumulation in the body of the inhibiting factor, which temporarily decreases the activity of macromolecular antibodies maintaining their physiological concentration; this prevents overstrain of the immune system. This phenomenon is eliminated in 2-3 days (Zhuravlyova, 1970).

\section{References}

1. Zemskov A.M., Esaulenko I.E., Chereshnev V.A., Zemskov V. M. et al. Immunology. Electronic Textbook. 2016. 127 author's sheets. (in Russian)

2. Novikova L.A., Zemskov A.M. New elements of pathogenesis and treatment of allergic skin vasculitis]. Voronezh: Publishing house "Voronezh State University”, 1998.256 p. (in Russian)

3. Zemskov A.M., Zemskov V.M., Sergeev Yu.V., Karaulov A.V. et al. non-pharmacological immunocorrection. Moscow: Publishing house "Natsional'naya akademiya mikologii”.2002b.264 p. (in Russian)

4. Goryaynov I.I. Immunomodulating effect of physiotherapeutic factors in the normal and pathological conditions characterized by the development of the secondary immunodeficiency. Thesis of Doct Diss.Moscow1999. 44 p. (in Russian)

5. Zubkova S.M. Comparative analysis of the biological effect of microwaves and laser irradiation. Journal Voprosy kurortologii.1996, № 36. pp. 31-34. (in Russian)

6. Alekhina O.D. Laser and magnetic-laser therapy in myocardial infarction: experimental study. Thesis of Cand. Diss. Voronezh.1994.22 p. (in Russian)

7. Konchugova T.V., Pershin E.B. Minenkov A.A. Immunomodulating effect of low intense laser irradiation. Journal Voprosy Kurortologii.1977. № 1. pp. 42-45. (in Russian)

8. Grinzayd Y.M., Babin L.Y., Ter-Gabriel'yants G.G. Immunomodulating effect of ultrasound in the physiological experiment. Journal Uspekhi fiziologicheskoy nauki [Advances of physiological science].1994. Vol. 2.№ 2. pp. 21-24. (in Russian) 
9. Dolgareva S.A. Immunotropic effect of ultrasound in the norm and in the physiological experiment. Thesis Cand. Diss. Kursk. 1998.19 p. (in Russian)

10. Chzhu Bin. Comparative assessment of the clinical efficiency of chronohydroacupuncture and chronolaseropuncture of patients with bronchial asthma. Thesis Cand. Diss. Voronezh.1997.21 p. (in Russian)

11. Fedenko E.S. Clinico-immunological characteristic of atopic dermatitis and investigation of extracorporal therapeutic methods. Thesis Cand. Diss. Moscow. 1987.19 p. (in Russian)

12. Zhestkov K.G. Immunological aspects of pathogenesis and treatment of complications in thoracic surgery. Thesis Doct. Diss.Voronezh.1999.36 p. (in Russian)

13. Zhestkov K.G., Zemskov V.M., Perel'man M.I., Kiryukhin A.Y. Local antituberculous immunity. Method of extraction of lymphocytes from tuberculous focus and their immunofluorescent analysis. Immunologiya [Immunology].1998a.№ 5. pp. 61-62. (in Russian)

14. Zhestkov K.G., Perel'man M.I., Zemskov V.M., Kiryukhin A.Y. Focus-infiltrating lymphocytes in pulmonary tuberculosis: the technique of extraction and immunofluorescent analysis. Byulleten' eksperimental'noy biologii $i$ meditsiny [Bulletin of experimental biology and medicine].1998b. vol.125. №3.pp. 353-355 (in Russian)
15. Zemskov A.M., Zemskov V. M., Chereshnev V.A. Encyclopedia of immunology in 5 volumes. Moscow: Publishing house «TRIADA-X».2002a. 263 p. (in Russian)

16. Kuno A.S. Cascade extracorporal blood treatment in bronchial asthma therapy. Thesis Cand. Diss. Voronezh. 1994. 20 p.(in Russian)

17. Kuz'menko A.V. Ozonetherapy by distant lithotripsy method in patients with kidney stone disease with comorbid pyelonephritis. Thesis Cand. Diss. Voronezh.1997.21 p. (in Russian)

18. Klimov E.V. Immunological rehabilitation and optimization of sulfide balneotherapy in patients with atopic dermatitis. Thesis Cand. Diss. Kursk. 1993.20 p. (in Russian)

19. Zemskov M. V., Zhuravleva N. V. Inhibition phenomenon of macromolecular antibodies. Invention USSR № 197.1977. (in Russian)

20. Zhuravleva N.V. Some immunological effects of bloodletting. Thesis Doct. Diss. Voronezh.1970.37 p. (in Russian)

\section{How to cite this article:}

AndreyM. Zemskov et al.2017, NON-Pharmacological Immunocorrection. Int J Recent Sci Res. 8(5), pp. 17140-17145.

DOI: http://dx.doi.org/10.24327/ijrsr.2017.0805.0291 